\title{
Gramsci e a crítica da economia política: estudos sobre o mercado determinado
}

\author{
Rodrigo Castelo ${ }^{1}$ \\ https://orcid.org/0000-0002-8927-1055 \\ ${ }^{1}$ Universidade Federal do Estado do Rio de Janeiro, Departamento de Serviço Social, Rio de Janeiro, RJ, Brasil
}

\section{Gramsci e a crítica da economia política: estudos sobre o mercado determinado}

Resumo: O presente texto apresenta uma análise da categoria de mercado determinado na obra de Antonio Gramsci, tanto nos Cadernos do cárcere como nas suas correspondências com Tatiana Schucht e Piero Sraffa. Nossos estudos apontam que a referida categoria é um dos pontos centrais da unidade dialética entre filosofia, economia e política nos Cadernos - as três fontes do marxismo, de acordo com Lenin -, unidade incontornável para o entendimento das elaborações gramscianas na sua totalidade. Nesta unidade, a crítica da economia política tem um peso considerável, o que nem sempre é reconhecido por comentadores da obra de Gramsci. Um dos nossos objetivos, portanto, é reavaliar o peso dos estudos sobre economia na teoria gramsciana.

Palavras-chave: Antonio Gramsci. Crítica da economia política. Mercado determinado.

\section{Gramsci and the critique of political economy: studies on the determined market}

Abstract: This article analyzes the determined market in work by Antonio Gramsci, both in the Prison Notebooks and in his correspondence with Tatiana Schucht and Piero Sraffa. The study points out that this category is one of the central points of the dialectical unity among philosophy, economy, and politics in the Notebooks (the three sources of Marxism, according to Lenin), an unavoidable unit for understanding the totality of Gramscian elaborations. In this unit, the critique of the political economy has considerable significance, which is not always recognized by commentators on Gramsci's work. One of the objectives of this article is to reassess the significance of studies on economics in Gramsci's theory.

Keywords: Antonio Gramsci. Criticism of political economy. Determined market.

Recebido em 28.01.2019. Aprovado em 17.09.2019. Revisado em 01.10.2009.

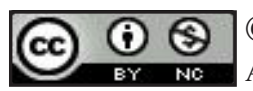

(C) O(s) Autor(es). 2020 Acesso Aberto Esta obra está licenciada sob os termos da Licença Creative Commons Atribuição-NãoComercial 4.0 Internacional (https://creativecommons.org/licenses/by-nc/4.0/deed.pt_BR), que permite copiar, distribuir e reproduzir em qualquer meio, bem como adaptar, transformar e criar a partir deste material, desde que para fins não comerciais e que você forneça o devido crédito aos autores e a fonte, insira um link para a Licença Creative Commons e indique se mudanças foram feitas. 


\section{Introdução}

Na vasta literatura especializada sobre Antonio Gramsci, poucos textos destacam suas contribuições ao pensamento econômico marxista. Comentadores da sua obra deixam de valorizar as notas carcerárias sobre a crítica da economia política, de modo que os apontamentos gramscianos sobre o tema ficam à sombra das suas categorias políticas, culturais e filosóficas.

Citemos dois exemplos ilustrativos que, de uma forma geral, reforçam a tese do divórcio de Gramsci com os debates econômicos. Ambos os exemplos vêm do mundo anglófono e de reconhecidos historiadores marxistas. Em uma das suas últimas publicações, Eric Hobsbawm (2011, p. 287) anotou que Gramsci "escreveu relativamente pouco sobre desenvolvimento econômico [...]". Décadas antes, em artigo publicado em 1975, o juízo de Hobsbawm acerca da presença da economia nos escritos de Gramsci era mais implacável: "Todos, com exceção talvez do economista, encontrarão iluminações nos Cadernos" (HOBSBAWM apud COUTINHO, 1999, p. 89, nota 15). Perry Anderson, por sua vez, no seu texto clássico As antinomias de Gramsci, que correu o mundo e gerou inúmeras polêmicas, emitiu um comentário ainda mais fulminante (e impreciso), frisando que, nos Cadernos do cárcere, "problemas tão centrais como a interconexão das lutas econômicas e políticas no movimento operário, [...] a natureza contemporânea das crises capitalistas [...], são todos omitidos aqui" (ANDERSON, 2002, p. 96-7).

\section{A filosofia política de Gramsci} só é inteligível se for combinada com seus estudos sobre a crítica da economia política. Nas notas sobre o mercado determinado, deparamo-nos com um dos pontos fulcrais da unidade dialética entre filosofia, economia e política nos

Cadernos, algo incontornável para o entendimento da totalidade das elaborações gramscianas.

De uns tempos para cá, uma nova safra de pesquisas contesta o suposto divórcio dos escritos gramscianos com a ciência econômica. Esta tendência é mundial e encontra forte apelo no Brasil. Um dos estudos pioneiros no nosso país em relacionar, de forma íntima e orgânica, política e economia na obra gramsciana, foram os escritos de Ruy Braga sobre o neoliberalismo e a reestruturação produtiva ocorrida nos anos 1980 e 1990 (BRAGA, 1995), que construiu a base material da estrondosa derrota histórica experimentada pela classe trabalhadora com o fim do socialismo real. Comumente visto somente como uma ideologia, o neoliberalismo é tratado, no texto de Braga (1995), sob a perspectiva da totalidade da estrutura e da superestrutura.

Sete anos depois, a revista Novos Rumos, do Instituto Astrojildo Pereira, publicou a tradução de um artigo de Luigi Cavallaro (2002) sobre a economia política de Gramsci, no qual o autor italiano faz uma síntese das contribuições dos Cadernos do cárcere na área econômica, com destaque para a categoria de mercado determinado, igualando-a à categoria marxiana de modo de produção. A tese central do artigo é a defesa da teoria da transição como alicerce estrutural das reflexões gramscianas e, para sustentar estas fundações, o revolucionário sardo teria se debruçado firmemente sobre as questões econômicas, mesmo que estas apareçam subsumidas às questões político-revolucionárias.

Na segunda década do século 21 , surgem três trabalhos nacionais que resgatam a importância dos estudos econômicos nas notas gramscianas. Virgínia Fontes, no livro $O$ Brasil e o capital-imperialismo, pesquisou as determinações contemporâneas do capitalismo a partir de estudos das expropriações, da produção do valor via a exploração da força de trabalho, da expansão imperialista e do uso combinado de coerção e consenso pelos Estados burgueses no pós-Segunda Guerra. Rompendo com alguns cânones, Gramsci não é reivindicado nesse livro apenas como um estudioso dos fenômenos superestruturais (embora esta seja a sua principal função na obra de Fontes nos debates sobre Estado ampliado), mas também como um dos teóricos que ajudam a pensar o imperialismo, complementando análises mais consagradas neste campo, como as de Vladimir Illitch Lenin (FONTES, 2010, p. 122).

Em 2013, dois livros de professores brasileiros reforçam a tese da ligação íntima das análises e da práxis revolucionária de Gramsci com os estudos econômicos. Alvaro Bianchi, no sexto capítulo de Arqueomarxismo, resgatou um artigo publicado em 2002 na revista Novos Rumos (a mesma que publicou o artigo de Cavallaro) e reafirmou que os estudos de Gramsci sobre as crises capitalistas, "refletindo sobre as relações entre estrutu- 
ra e superestrutura", é uma tentativa de "[...] estabelecer as relações existentes entre política e economia" (BIANCHI, 2013, p. 127). No mesmo ano, O social-liberalismo foi lançado, no qual Rodrigo Castelo faz um uso sistemático de categorias gramscianas - bloco histórico, crise orgânica, revolução passiva, Estado ampliado, intelectuais, ideologia e outras - para compreender novas determinações econômicas, políticas e ideológicas do capitalismo na era neoliberal, com destaque para a atuação do grande capital nas expressões da "questão social" (CASTELO, 2013).

Por fim, mas sem esgotar a lista de comentadores que relacionam política e economia na obra do comunista italiano, Peter Thomas (2018, p.176), em artigo recentemente publicado na revista Outubro, explanou que "[...] os Cadernos possuem muitas notas dedicadas ao problema da história econômica, da teoria econômica burguesa e à crítica marxista da economia política. Não são apenas comentários marginais de um neófito, mas discussões sofisticadas de temas altamente técnicos [...]".

O objetivo do presente artigo não é questionar a centralidade da política nos escritos gramscianos - tese com a qual temos acordo -, mas jogar luzes nas suas vívidas contribuições à crítica da economia política inaugurada por Marx e que teve largo fôlego nos últimos 150 anos na tradição marxista. As contribuições gramscianas aparecem nas notas carcerárias sobre mercado determinado, crise orgânica, bloco histórico, lei tendencial de queda da taxa de lucro, americanismo-fordismo, a relação do Estado burguês com a acumulação capitalista, etc., e estão imbricadas nos debates da revolução proletária e das contrarrevoluções e revoluções passivas burguesas, a tal ponto que não podem ser dissociadas umas das outras.

Dentre estas categorias, o presente texto abordará a de mercado determinado, analisando as aparições nos Cadernos do cárcere em ordem cronológica proposta no verbete da referida categoria, escrito por Fabio Frosini e publicado no Dicionário Gramsciano (LIGUORI; VOZA, 2017, p. 528-9). Outra fonte sobre o mercado determinado é o epistolário de Gramsci, em especial as cartas endereçadas a Tatiana Schucht e a Piero Sraffa.

A filosofia política de Gramsci só é inteligível se for combinada com seus estudos sobre a crítica da economia política. Nas notas sobre o mercado determinado, deparamo-nos com um dos pontos fulcrais da unidade dialética entre filosofia, economia e política nos Cadernos, algo incontornável para o entendimento da totalidade das elaborações gramscianas.

\section{O mercado determinado}

As formulações de Gramsci sobre o mercado determinado são fruto de uma gama de estudos: 1. das polêmicas entre pensadores italianos - Benini, Einaudi, Graziadei, Jannaconne, Spirito - sobre ciência econômica e a relação entre Estado e economia; 2. do debate filosófico sobre ciência, historicismo, imanência, leis de tendência e regularidade; 3 . da história do pensamento econômico e suas controvérsias entre economia política clássica, marxismo e marginalismo e; 4 . da sua interpretação da filosofia da práxis como síntese de três fontes (filosofia clássica alemã, economia política inglesa e filosofia política francesa).

A categoria de mercado determinado tem poucas inserções nos Cadernos, mas o seu peso não deve ser desprezado. Ela aponta para a construção de uma unidade dialética entre estrutura e superestrutura, algo essencial no método marxista, e que servirá para análises concretas de situação concreta. A filosofia da práxis gramsciana é um duplo combate, tanto às tendências economicistas do marxismo vulgar como ao voluntarismo - quase sempre acompanhado de altas doses de sectarismo - de posições políticas baseadas exclusivamente na vontade política, sem uma análise aprofundada da correlação de forças presente em uma determinada conjuntura. Na nota $\$ 52$ do Caderno 11, Gramsci (1999, p. 197) sintetiza os princípios metodológicos basilares do materialismo histórico:

Na premissa devem estar contidas, já desenvolvidas, as condições materiais necessárias e suficientes para a realização do impulso da vontade coletiva; mas é evidente que desta premissa "material", quantitativamente calculável, não pode ser destacado um certo nível de cultura, isto é, um conjunto de atos intelectuais, e destes (como seu produto e consequência), um certo complexo de paixões e de sentimentos imperiosos, isto é, que tenham a forma de induzir à ação "a todo custo".

A primeira aparição da categoria é na nota $\$ 30$ do Caderno 7, escrita em fevereiro de 1931, na qual Gramsci afirma que o mercado determinado é um dos "conceitos fundamentais da ciência econômica" e deve ser relacionado aos estudos da teoria do valor-trabalho e da concorrência ou do monopólio, bem como às variações entre estes dois extremos, que não devem ser considerados puros (GRAMSCI, 1999, p. 442).

No ano seguinte, no mês de março, Gramsci volta ao tema com mais densidade. A nota §216 do Caderno 8 rastreia a origem da categoria na economia política clássica, escola injustamente acusada de ser "naturalista" 
e "determinista" de acordo com a sua avaliação. Esta acusação seria infundada, pois a base filosófica dos economistas clássicos seria o historicismo, a despeito das suas abstrações e da linguagem matemática. Assim, Gramsci coloca uma pergunta e, logo em seguida, a resposta:

Mas o que é o "mercado determinado" e pelo que, precisamente, ele é determinado? Será determinado pela estrutura fundamental da sociedade em questão e, então, será preciso analisar esta estrutura e identificarlhe os elementos que, relativamente constantes, determinam o mercado, etc., e os outros elementos "variáveis e em desenvolvimento", que determinam as crises conjunturais, até o momento em que também os elementos "relativamente constantes" sejam por estes modificados, ocorrendo assim a crise orgânica. (GRAMSCI, 1999, p. 446-447).

Nesta passagem, retoma-se em parte o que já havia escrito no Caderno 7, em que se afirma que o mercado é determinado por questões da base econômica, como a estrutura de concorrência e monopólio e a produção da riqueza. A isto, agrega-se os temas das crises capitalistas - conjunturais ou orgânicas e dos elementos variáveis e constantes de uma época histórica. Nesta segunda aparição, salta aos olhos a relação estabelecida entre mercado determinado e crises capitalistas, o que fortalece a hipótese de que a categoria de crise orgânica não é equivalente à de crise de hegemonia, o que é visto com frequência nos comentadores gramscianos. Nessa nota, a crise orgânica está relacionada diretamente (mas não somente) ao abalo dos elementos constantes do mercado determinado, isto é, para que haja uma crise orgânica deve haver modificações na estrutura econômica de uma determinada formação econômico-social (ou, de forma mais geral, a um modo de produção), aliadas a modificações nas superestruturas políticas, ideológicas, jurídicas etc. Portanto, a categoria de crise orgânica busca dar conta tanto de fenômenos estruturais como superestruturais.

Mais à frente, na nota $\$ 216$, numa avaliação de artigos de Einaudi, Gramsci destaca que o mercado determinado tem uma configuração histórica inédita no início do século 20 , se comparado com o século 19 . O setor produtivo e o mercado internacionais, bem como a escala oligopólica de produção e o aumento do nível de renda de praticamente todas as classes, elevaram o mercado determinado a um novo patamar, o que modificou radicalmente a natureza e os impactos das crises capitalistas, sendo impossível saídas fáceis para tais fenômenos. Nesse sentido, Gramsci afirma que a crise capitalista vivenciada no seu tempo é uma crise orgânica, e não conjuntural, como quis Einaudi. A diferença entre as duas reside "[...] pela sua amplitude e profundidade, que atingiram tal ponto que a quantidade se torna qualidade [...]". (GRAMSCI, 1999, p. 447) Novamente, a crise orgânica é tida como um evento relacionado com as mudanças operadas no nível da base econômica, e não apenas como uma perda de hegemonia das classes dominantes junto aos seus aliados táticos e estratégicos e setores conformistas das classes subalternas.

Em maio de 1932, o Caderno 10 (II) é preenchido com a nota $§ 9$, na qual fica mais claro que David Ricardo é a principal fonte de Gramsci a respeito dos princípios historicistas da economia política clássica. Sabe-se que o conhecimento de Gramsci acerca da obra ricardiana não vem de uma leitura dos originais ${ }^{1}, o$ que prejudica as suas avaliações, mas sim do estudo de compêndios de história do pensamento econômico e do livro IV de $O$ capital, intitulado postumamente de Teorias da mais-valia. Mesmo assim, Gramsci rabisca linhas ousadas sobre o teor filosófico da obra ricardiana e seus impactos no método marxiano.

Nessa nota, denominada Introdução ao estudo da filosofia. Imanência especulativa e imanência historicista ou realista, a filosofia da práxis é tida como uma síntese teórica criada, na perspectiva classista proletária e de um projeto socialista revolucionário, a partir de três escolas de pensamento: a filosofia clássica alemã, a economia política inglesa e a política francesa (GRAMSCI, 1999, p. 317). Esta é uma formulação originariamente desenvolvida num escrito de Karl Kautsky de 1908 sobre as três fontes do marxismo, e que fora retomada por Lenin cinco anos depois. A novidade trazida por Gramsci é questionar o peso filosófico da obra ricardiana na síntese teórica operada por Marx, o que nem Kautsky nem Lenin ousaram fazer. Conforme anotação nos Cadernos,

em um certo sentido, é possível dizer que a filosofia da práxis é igual a Hegel + David Ricardo. O problema, inicialmente, deve ser apresentado da seguinte maneira: os novos cânones metodológicos introduzidos por Ricardo na ciência econômica devem ser considerados como valores meramente instrumentais (entenda-se: como um novo capítulo da lógica formal) ou terão um significado de inovação filosófica? A descoberta do princípio lógico formal da "lei tendencial", que conduz à definição científica dos conceitos fundamentais na economia, o de homo economicus e o de "mercado determinado", não foi uma descoberta de valor também gnosiológico? Não implica, precisamente, uma nova "imanência", uma nova concepção da "necessidade" e da liberdade, etc.? (GRAMSCI, 1999, p. 317-318). 
Logo abaixo desta anotação, Gramsci demarca a origem histórica das categorias de lei tendencial e mercado determinado na consolidação da burguesia como classe hegemônica mundial no período da divisão internacional do trabalho comandada pela Inglaterra em meados do século 19. Nesta época, de acordo com a consolidação de novas configurações do capitalismo, tornou-se possível estudar cientificamente os elementos regulares de desenvolvimento ${ }^{2}$ do mercado mundial, isolando - isto é, abstraindo-se - os elementos perturbadores da análise. Isto permitiu a previsão das leis tendenciais da nova fase do capitalismo, "que são leis não no sentido naturalista e determinista especulativo, mas em sentido "historicista', isto é, na medida em que exista o 'mercado determinado', ou seja, um ambiente organicamente vivo e articulado em seus movimentos de evolução". (GRAMSCI, 1999, p. 318).

Esta forma de tratamento do objeto permite a Gramsci criar uma metodologia de recorte histórico do modo de produção capitalista em fases, as chamadas concorrencial e monopolista. Tais fases atingem um determinado grau de regularidade do seu desenvolvimento após a consolidação de fenômenos históricos amplos e profundos (revoluções burguesas clássicas, crises orgânicas, revoluções passivas, novas escalas de produção, divisão internacional do trabalho e o mercado mundial, nova correlação de forças, etc.), permitindo aos cientistas sociais formularem uma teorização abstrata (não metafísica nem determinista, mas imanentemente histórica) sobre as contradições da estrutura de produção e superestrutura político-cultural que impulsionam a mudança de uma fase do modo de produção capitalista para uma outra. Ao invés de repetir fórmulas gastas e citações impactantes das obras de Marx, Engels e Lenin, Gramsci tinha como objetivo trazer à baila as novas determinações históricas do capitalismo e desenhar, de forma inovadora, um cenário para a atuação revolucionária da classe trabalhadora condizente com a nova realidade. Como diz José Aricó (2012, p. 247, tradução nossa),

[...] o mais significativo é o fato fundamental de que para Gramsci a solução dos grandes problemas estratégicos do movimento revolucionário passava necessariamente pela reativação das categorias da crítica da economia política e pela tentativa de voltar a fundar a teoria marxista no nível das novas formas que adquiria o modo de produção capitalista.

No nosso entendimento, ao contrário do que afirma Luigi Cavallaro ${ }^{3}$, Gramsci resgata a categoria de mercado determinado da economia política clássica para entender as mudanças regulares e traçar leis tendenciais dentro do modo de produção capitalista, e não igualando-a à categoria de modo de produção. $\mathrm{O}$ estudo das fases do capitalismo é realizado pelo preso político a partir das considerações de Lenin sobre o imperialismo, mas é incrementado pela originalidade sempre presente nas intervenções gramscianas. Esta originalidade tem como fundamento os debates políticos travados por Gramsci dentro da Internacional Comunista, na qual a sua cúpula insistia, sob a autocracia estalinista, nas teses de uma crise final do capitalismo no final dos anos 1920 e início dos 1930 e da inevitabilidade da revolução socialista, como se o desdobramento natural de uma crise capitalista fosse a ascensão do proletariado ao poder. O que deveria ser apreendido como uma condição necessária à revolução socialista, foi tornada condição suficiente, pavimentando o caminho para derrotas das forças proletárias.

Ora, para Gramsci, não há uma relação mecânica entre crise capitalista e revolução socialista, e esta crítica à linha oficial adotada pela Internacional Comunista a partir do seu VI Congresso foi, de maneira sempre cifrada, reafirmada nos Cadernos. O rompimento dos elos que ligam estrutura e superestrutura em uma fase histórica do modo de produção capitalista pode levar, a depender da correlação de forças existentes no momento das crises orgânicas (ou das situações revolucionárias, como diria Lenin) a dois caminhos básicos: (1) à eclosão das revoluções socialistas, que podem romper com o capitalismo, caso venham a se estabelecer, ou (2) a formas de rearranjo das forças burguesas que articulam mudança de fases históricas dentro do modo de produção capitalista.

A proposição de Cavallaro acerca da centralidade da teoria da transição na obra gramsciana é acertada, pois os escritos do líder político italiano baseiam-se na realização da estratégia revolucionária proletária para a superação do modo de produção capitalista nas condições históricas do início do século 20 . Tais condições estavam marcadas pelas vitórias conquistadas pelos bolcheviques na Rússia, que desaguou na transição do modo de produção capitalista para o socialista, mas também pela posterior estagnação da insurreição revolucionária com as derrotas proletárias na Alemanha, Hungria e, especialmente, na Itália, que resultaram nas mudanças de fase histórica no interior do capitalismo.

Gramsci extraía lições dos êxitos revolucionários, mas as derrotas proletárias não passavam desapercebidas, o que constitui uma marca dos Cadernos. As suas teorizações ampliaram-se para além da transição socialista e comportaram sugestivas notações sobre as transformações do bloco histórico dentro do modo de produção capitalista, no caso concreto, da fase concorrencial para a monopolista. Estas mudanças de fase histórica deram-se a partir de distintas táticas das classes dominantes, como, por exemplo, as 
revoluções passivas do fascismo e do americanismo-fordista. Para os estudos dessas mudanças entre fases no capitalismo, Gramsci utilizou-se em diversos momentos da categoria de mercado determinado, junto com as de crise orgânica e conjuntural. A hipótese de Cavallaro não leva em consideração, portanto, as transformações qualitativas e quantitativas dentro do modo de produção capitalista que operam mudanças de uma fase histórica para outra -, algo que Gramsci faz em algumas das passagens mais marcantes nos seus apontamentos sobre o mercado determinado.

Numa carta de 30 de maio de 1932 endereçada a Tatiana Schucht, o líder comunista pede a sua cunhada que entre em contato com Piero Sraffa para saber se há uma bibliografia especializada sobre o método científico de David Ricardo. Tais inquietações já estavam presentes na nota $\$ 9$ do Caderno 10 (II), mas Gramsci as reafirma nessa carta e vai além nas suas interrogações: o método de Ricardo contribuiu para Marx superar a dialética hegeliana e criar a sua própria síntese metodológica? De acordo com o seu questionamento, as categorias de mercado determinado e lei de tendência podem ser entendidas como

um impulso para converter a concepção "imanentista" da história - expressa com linguagem idealista e especulativa da filosofia clássica alemã - numa "imanência" realista imediatamente histórica, na qual a lei de causalidade das ciências naturais foi depurada de seu mecanismo e se identificou sinteticamente com o raciocínio dialético do hegelianismo? (GRAMSCI, 2005, p. 205).

Gramsci suspeita da validade das suas proposições e admite que são "um pouco confusas". Todavia, a sua notória inquietação o impulsiona a investigar se a economia política inglesa contribuiu com a obra marxiana para além da teoria do valor-trabalho. No dia 21 de junho, Sraffa responde a Tatiana. Na sua missiva, o economista italiano escreve que precisa meditar sobre o assunto e estudar mais a fundo as obras dos fundadores do marxismo. Mas, deixando de lado as suas reticências, Sraffa complementa assertivamente que precisa de

algumas explicações sobre os dois conceitos de "mercado determinado" e de "lei de tendência", que Nino chama de fundamentais e aos quais, colocando entre aspas, parece atribuir um significado técnico: confesso que não compreendo bem a que se referem e, quanto ao segundo, estava acostumado a considerá-lo, antes, como uma das características da economia vulgar. De todo modo, é muito difícil avaliar a importância filosófica, se é que existe, de Ricardo, porque ele mesmo, ao contrário dos filósofos da práxis, não se propôs nunca considerar historicamente seu próprio pensamento. (SRAFFA apud GRAMSCI, 2005, p. 206-7, nota 3).

Sraffa praticamente desautoriza as especulações gramscianas acerca da contribuição do método de Ricardo na construção do materialismo histórico enquanto nova síntese filosófica, questionando também a pertinência e validade das categorias de mercado determinado e lei tendencial. O peso das suas palavras é enorme, pois as opiniões de Sraffa eram acompanhadas do seu reconhecimento como a maior autoridade do século 20 sobre a obra de Ricardo. Apesar das duras palavras do seu amigo e camarada, Gramsci não recuou das suas formulações heréticas.

Uma nova face da categoria mercado determinado surge na nota §20 do Caderno 10 (II), escrita no mês de junho de 1932 e que versa sobre as polêmicas entre Einaudi, Spirito e Benini sobre concepções de Estado e suas formas de intervenção na economia. Discordando tanto do liberalismo de Einaudi como do corporativismo de Spirito, Gramsci recupera reflexões de Benini sobre o tema, pois este autor, apesar da linguagem liberal, partira dos princípios da economia política, a saber, dos elementos estruturais do mercado determinado. Este procedimento metodológico permite identificar o Estado como uma instituição que atua constantemente na acumulação capitalista e sob um viés classista. O exemplo desta intervenção é a desvalorização da força de trabalho em prol do capital. De acordo com Gramsci (1999, p. 328), a intervenção estatal

é uma condição preliminar de qualquer atividade econômica coletiva, é um elemento do mercado determinado, se não for precisamente o próprio mercado determinado, já que é a expressão político-jurídica do fato de que uma determinada mercadoria, o trabalho, é preliminarmente depreciada, colocada em condição de inferioridade competitiva, paga por todo o sistema determinado.

Até então, a categoria de mercado determinado não havia sido relacionada diretamente com o Estado. E Gramsci vai além quando insinua que o Estado pode ser o próprio mercado determinado. Ele parece se referir ao processo de formação e mercantilização da força de trabalho na Inglaterra, ocorrido na assim chamada acumulação primitiva do capital, e à intervenção do Estado, desde as Leis dos Pobres, para disciplinar a força de trabalho e aviltar os salários mediante o uso intensivo e perene dos seus aparelhos coercitivos. Vale notar que, para Gramsci, a depreciação do trabalho não se esgota numa era antiga do capitalismo, mas continua 
atuando na etapa monopolista pós-Primeira Guerra Mundial. O mercado determinado seria, desta forma, uma categoria que expressa teoricamente a intervenção do Estado desde a gênese do modo de produção capitalista até a fase monopolista, resguardadas as devidas mediações históricas.

Repetida exaustivamente para se tornar uma verdade inquestionável, a tese do Estado mínimo - que reúne evidências históricas contrárias ${ }^{4}$ - é questionada por Gramsci a partir das suas notas sobre o mercado determinado. De meados do século 18 até meados do 19, as principais obras econômicas consagraram a expressão 'economia política'. Para nascer enquanto um ramo autônomo da ciência, a economia precisou romper laços com a moral, a teologia e até mesmo com a filosofia política, mas este rompimento, em particular com a política, foi parcial, e a autonomia científica da economia se tornou relativa.

Para ganhar sua autonomia relativa, a linha hegemônica da ciência econômica deixou muitos elementos para trás, mas questões essenciais da política se conservaram no novo ramo teórico até pelo menos o período da decadência ideológica burguesa, inaugurada em 1848 com a Primavera dos Povos. Alguns livros da economia política traziam, nos seus títulos, temáticas de política econômica, como é o caso de David Ricardo e a sua brochura mais conhecida, Princípios de economia política e tributação (1817). Na introdução do livro quarto de A riqueza das nações (1776), Adam Smith, notoriamente consagrado como o pai do liberalismo econômico e teórico da mão invisível do mercado, chega a dizer que a economia política é "um setor da ciência própria de um estadista ou de um legislador [...]" (SMITH, 1983, p. 357); o livro quinto, chamado A receita do soberano ou do Estado, é o segundo mais extenso de toda a obra, só ficando atrás, em número de página, do primeiro livro, dedicado ao tema do trabalho como produtor de valor. "Na verdade", diz Aloisio Teixeira (2000, p. 93-94),

a expressão economia política está, em sua origem, relacionada a seu inverso, a política econômica - e, portanto, a processos e decisões que envolvem atores reais no campo da política, suas paixões e interesses. $\mathrm{O}$ momento histórico em que o interesse por assuntos econômicos vai atraindo um número crescente de pensadores, não só provenientes do campo da filosofia política, mas também homens com formação voltada para problemas práticos, é exatamente o momento da formação dos Estados nacionais e da generalização das relações mercantis. Tais processos colocaram, de forma renovada, o problema da gestão das políticas públicas, fazendo com que atividades, como as relacionadas com finanças e tesouraria, adquirissem nova importância.

Ao relacionar o mercado determinado à fase concorrencial do capitalismo, Gramsci se afasta do mito do "Estado mínimo", que somente garantiria as condições gerais de produção, a segurança e a propriedade privada, mantendo-se ausente de uma intervenção mais sistemática na acumulação capitalista. Nada mais distante da realidade e da doutrina liberal, apontou Gramsci em notas do Caderno do cárcere, inclusive em algumas que não discutem o mercado determinado. No Caderno 8 (1931-1932), nota §185, Gramsci (2002, p. 286) escreve o seguinte sobre transições históricas de modos de produção:

Se é verdade que nenhum tipo de Estado pode deixar de atravessar uma fase de primitivismo econômicocorporativa, disso se deduz que o conteúdo da hegemonia política do novo grupo social que fundou o novo tipo de Estado deve ser predominantemente de ordem econômica: trata-se de reorganizar a estrutura e as relações reais entre os homens e o mundo econômico ou da produção.

Na nota acima, o raciocínio de Gramsci vale tanto para transições históricas do modo de produção feudal para o capitalista, como do capitalista para o socialista. Em ambos os casos, o Estado, conquistado por novos setores da sociedade civil (isto é, pelas novas classes dominantes), tomou medidas enérgicas de reformulação da base econômica. Essa constatação evidencia o papel ativo da superestrutura política nas transformações estruturais e quebra qualquer automatismo ou mecanicismo na relação entre base e superestrutura advogado por correntes vulgares do marxismo. O papel ativo e o peso histórico da vontade política são reafirmados, em especial nos momentos de transição revolucionária entre modos de produção.

No caso da transição do feudalismo para o capitalismo, tal qual Marx ressaltou no capítulo 24 do livro I de O capital na sua fórmula da violência como potência econômica (CASTELO; RIBEIRO; LIMA, 2018, p. 266-271), o Estado foi uma ferramenta fundamental nas mãos da burguesia, e continuou a sê-lo depois na manutenção da sua supremacia de classe. Imediatamente após as revoluções burguesas de tipo jacobino, que inauguram a fase concorrencial do capitalismo, a burguesia e seus aliados não renunciaram à máquina política estatal como instrumento de força e consenso, incluindo seus aparatos coercitivos de política econômica. Na nota §6 do Caderno 26, datado de 1935, a posição contrária à tese mítica do "Estado mínimo" fica ainda mais evidente:

Na polêmica (de resto, superficial) sobre as funções do Estado (e entenda-se Estado como organização político-jurídica em sentido estrito), a expressão "Estado veilleur de nuit" ("Estado guarda-noturno") 
corresponde em italiano a Estado carabiniere e quer significar um Estado cujas funções se limitam à tutela da ordem pública e do respeito às leis. Não se insiste no fato de que nesta ordem de regime (que, afinal, jamais existiu a não ser no papel, como hipótese-limite) a direção do desenvolvimento histórico cabe às forças privadas, à sociedade civil, que também é “Estado”, aliás, é o próprio Estado. (GRAMSCI, 2007, p. 85).

Na nota $§ 52$ do Caderno 11, provavelmente redigida entre agosto e final de 1932, Gramsci reescreve a nota $§ 128$ do Caderno 8, datada de abril do mesmo ano. Neste novo apontamento, intitulado Regularidade e necessidade, é retomada a discussão metodológica das leis de tendência do desenvolvimento capitalista na obra marxiana ${ }^{5}$, notadamente a lei geral da acumulação capitalista e a lei tendencial de queda da taxa de lucro. Além disso, ele ainda arrisca algumas linhas sobre a história do pensamento econômico. A questão central levantada é saber como a "economia crítica" (o marxismo) recolhe e traduz, sob nova linguagem, o historicismo da economia política clássica, afastando-se dos métodos a-históricos, generalistas e naturalizadores da "economia pura" (os marginalistas). Apesar de todas as notações críticas de Marx sobre o método da economia política - nas quais expressava profundos desacordos até mesmo com aqueles escritores que tinha em elevada estima científica, como Smith e Ricardo - e da resposta atravessada de Sraffa à sua carta de maio de 1932 , Gramsci não desanimou e voltou a insistir na hipótese, de difícil sustentação, da contribuição ricardiana ao método do materialismo histórico. Mas é aqui, na primeira parte da nota 52, que a categoria de mercado determinado aparece saturada de múltiplas determinações, sintetizando economia, política e filosofia como nunca havia sido feito nos Cadernos. Escreve Gramsci (1999, p. 194):

Conceito e fato de "mercado determinado", isto é, observação científica de que determinadas forças decisivas e permanentes surgiram historicamente, forças cuja ação se manifesta com um certo "automatismo", que permite um certo grau de "previsibilidade" e de certeza para o futuro com relação às iniciativas individuais que se adequam a tais forças, após tê-las intuído e compreendido cientificamente. "Mercado determinado" equivale, portanto, a dizer "determinada correlação de forças sociais em determinada estrutura do aparelho de produção", correlação que é garantida (isto é, tornada permanente) por uma determinada superestrutura política, moral, jurídica).

Nesta formulação, mercado determinado surge como uma síntese, materializada num bloco histórico, da correlação de forças entre as classes sociais fundamentada num determinado arranjo da base produtiva, sob os auspícios de uma superestrutura necessária à manutenção das configurações estruturais. Economia e política, produção e classes sociais, estrutura e superestrutura são tratados como uma totalidade viva no devir histórico, sempre em transformação (embora operem elementos de "automatismo" e "previsibilidade"), configurando uma nova fase histórica do modo de produção capitalista.

A nota $\$ 52$ do Caderno 11 é o último e mais bem acabado registro sobre o mercado determinado. Depois disto, a categoria perde fôlego. Entre junho e agosto, Gramsci redige as notas $\$ 30$ e $\$ 32$ de redação única (tipo B) no Caderno 10 (II). Nelas, dialoga com o livro Principi di economia pura de Pantaleoni e teoriza sobre a história do pensamento econômico, discutindo como diferentes categorias, aqui inclusa a de mercado determinado, ganham um tratamento histórico na economia crítica e um tratamento genérico na economia pura.

\section{Considerações finais}

Em linhas gerais, a categoria de mercado determinado permite-nos entender com mais precisão a forma dialética como Gramsci elaborou as suas análises concretas de situação concreta, na melhor tradição do marxismo em contraponto ao economicismo e determinismo reinante na II Internacional e na fase estalinista da III Internacional. A filosofia da práxis é uma síntese de três fontes teóricas, e esta síntese fica patente na categoria do mercado determinado, operando como uma chave heurística de interpretação das mudanças de fases do capitalismo. Esses períodos de transformação social são abertos pelas crises orgânicas, vistos por Gramsci como janelas históricas na qual a atuação firme e embasada teoricamente do proletariado permite tornar a crise numa situação revolucionária e, quiçá, na revolução social. Mas, como vimos, nem sempre a crise orgânica transmuta-se na transição socialista, pois as forças burguesas operam no sentido de neutralizálas, seja com a contrarrevolução, seja com as revoluções passivas.

Em tempos de crise orgânica capitalista, no Brasil e no mundo, nada mais atual do que nos voltarmos para o estudo das notas gramscianas de mercado determinado para avançarmos, não só na interpretação das atuais configurações da "questão social", mas também na reorganização da classe trabalhadora com o objetivo de (re)colocarmos o seu projeto autônomo e classista como uma saída real à crescente barbárie capitalista. 


\section{Referências}

ANDERSON, Perry. As antinomias de Gramsci. In: ANDERSON, Perry. Afinidades seletivas. São Paulo: Boitempo, 2002. p. 15-100. ARICÓ, José. Nueve leciones sobre economía y politica en el marxismo: curso de El Colegio de México. Buenos Aires: Fondo de Cultura Económica; El Colegio de México, 2012.

BIANCHI, Alvaro. Arqueomarxismo: comentários sobre o pensamento socialista. São Paulo: Alameda, 2013.

BRAGA, Ruy. Luta de classes, reestruturação produtiva e hegemonia. In: KATZ, Claudio et al. Novas tecnologias: crítica da atual reestruturação produtiva. São Paulo: Xamã, 1995. p.45-136.

CASTELO, Rodrigo. O social-liberalismo: auge e crise da supremacia burguesa na era neoliberal. São Paulo: Expressão Popular, 2013. CASTELO, Rodrigo; RIBEIRO, Vinicius; LIMA, Ricardo de. A violência como potência econômica: da acumulação primitiva ao novo imperialismo. In: BOSCHETTI, Ivanete (org.). Expropriação e direitos no capitalismo. São Paulo: Cortez, 2018. p. 265-292.

CAVALLARO, Luigi. A economia política de Gramsci. Novos Rumos, v. 17, n. 38, p. 4-13, 2002.

COUTINHO, Carlos Nelson. Gramsci: um estudo sobre seu pensamento político. 2. ed. Rio de Janeiro: Civilização Brasileira, 1999. FONTES, Virgínia. O Brasil e o capital-imperialismo: teoria e história. Rio de Janeiro: Editora da UFRJ; Escola Politécnica de Saúde Joaquim Venâncio, 2010.

GRAMSCI, Antonio. Carta de 7 de setembro de 1931 a Tatiana Schucht. In: GRAMSCI, Antonio. Cartas do cárcere, v. 2 (1931-1937). Rio de Janeiro: Civilização Brasileira, 2005. p. 82-5. ISBN 9788520006931.

GRAMSCI, Antonio. Carta de 30 de maio de 1932 a Tatiana Schucht. In: GRAMSCI, Antonio. Cartas do cárcere, v. 2 (1931-1937). Rio de Janeiro: Civilização Brasileira, 2005. p. 204-7. ISBN 9788520006931.

GRAMSCI, Antonio. Cadernos do cárcere, v. 1. Introdução ao estudo da filosofia. A filosofia de Benedetto Croce. Rio de Janeiro: Civilização Brasileira, 1999.

GRAMSCI, Antonio. Cadernos do cárcere, v. 3. Maquiavel. Notas sobre o Estado e a política. Rio de Janeiro: Civilização Brasileira, 2002.

GRAMSCI, Antonio. Cadernos do cárcere, v. 4. Temas de cultura, Ação Católica. Americanismo e fordismo. 2. ed. Rio de Janeiro: Civilização Brasileira, 2007.

HOBSBAWM, Eric. A era das revoluções (1789-1848). 17. ed. Rio de Janeiro: Paz e Terra, 2003.

HOBSBAWM, Eric. Como mudar o mundo: Marx e o marxismo. São Paulo: Cia. das Letras, 2011.

LIGUORI, Guido; VOZA, Pasquale (org.). Dicionário gramsciano (1926-1937). São Paulo: Boitempo, 2017.

MARX, Karl. Prefácio à primeira edição. In: O capital: crítica da economia política, livro I. São Paulo: Boitempo, 2013, p. 77-81.

POLANYI, Karl. A grande transformação: as origens da nossa época. Rio de Janeiro: Elsevier, 2000.

SMITH, Adam. A riqueza das nações, v. 1 e 2. São Paulo: Abril Cultural, 1983.

TEIXEIRA, Aloisio. Marx e a economia política: a crítica como conceito. In: Econômica, Niterói, n. 4, p. 85-109, dez. 2000.

THOMAS, Peter. “A virada de Moscou”: o diálogo de Gramsci e os bolcheviques (1922-1923). Outubro, São Paulo, n. 30, p. 173189 , maio 2018.

\section{Notas}

1 Na carta escrita no dia 7 de setembro de 1931 para Tatiana Schucht, Gramsci diz o seguinte: "Li, num artigo do senador Einaudi, que Piero está preparando uma edição crítica do economista inglês David Ricardo; Einaudi elogia muito a iniciativa e eu também fico muito contente. Espero ser capaz de ler corretamente o inglês quando esta edição for publicada e poder ler Ricardo no texto original". (GRAMSCI, 2005, p. 84).

2 No já citado prefácio da primeira edição do livro I de O capital, assim como no posfácio à segunda edição alemã, Marx dá pistas valiosas do seu método e anota que a completude da análise teórica de um objeto dado está condicionada pelo próprio estágio de desenvolvimento do objeto. “A forma de valor, cuja figura acabada é a forma-dinheiro, é muito simples e desprovida de conteúdo. Não obstante, o espírito humano tem procurado elucidá-la em vão há mais de 2 mil anos, ao mesmo tempo que obteve êxito, ainda que aproximado, na análise de formas muito mais complexas e plenas de conteúdo. Por quê? Porque é mais fácil estudar o corpo desenvolvido do que a célula que o compõe”. (MARX, 2013, p. 77-8).

3 Logo na primeira página do seu artigo, Cavallaro (2002, p. 4) afirma o seguinte: "Com efeito, é a partir desse conceito [modo de produção] - que, como veremos, assume uma outra denominação, a de 'mercado determinado' - que Gramsci esboça nas páginas dos Cadernos aparentemente dedicadas à economia política, o que, a meu ver, parece-me o núcleo central de seu pensamento: vale dizer, uma teoria da transição [...]”'.

4 Karl Polanyi (2000, p. 290) escreveu que "a história econômica mostra que a emergência de mercados nacionais não foi, de forma alguma, o resultado da emancipação gradual e espontânea da esfera econômica do controle governamental. Pelo contrário, o mercado foi a consequência de uma intervenção consciente, e às vezes violenta, por parte do governo que impôs à sociedade a organização do mercado, por finalidades nãoeconômicas". Numa outra perspectiva histórica, Eric Hobsbawm (2003, p. 269) registra, no livro A era das revoluções (1789-1848) que “[...] é um erro elementar (não compartilhado por esses protagonistas lógicos do capitalismo, os 'filósofos radicais' partidários de Bentham) acreditar que o liberalismo era hostil à burocracia. Ele era somente hostil à burocracia ineficaz, à interferência pública em assuntos que ficariam melhor se deixados para a empresa privada, eà tributação excessiva. O slogan liberal vulgar de um Estado reduzido às atrofiadas funções de um vigia noturno obscurece o fato de que o Estado destituído de suas funções ineficazes e inadequadas era um Estado muito mais poderoso e ambicioso do que antes". 
5 No prefácio da primeira edição do livro I de O capital, Marx refere-se, em duas passagens, a importância na sua obra da descoberta das leis tendenciais do desenvolvimento capitalista, inclusive em termos da revolução proletária: "Ainda que uma sociedade tenha descoberto a lei natural do seu desenvolvimento - e a finalidade última desta obra é desvelar a lei econômica do movimento da sociedade moderna-, ela não pode saltar suas fases naturais de desenvolvimento, nem suprimi-las por decreto. Mas pode, sim, abreviar e mitigar as dores do parto”. (MARX, 2013, p. 79).

\section{Rodrigo Castelo}

rodrigo.castelo@gmail.com

Doutor em Serviço Social pela Universidade Federal do Rio de Janeiro (UFRJ)

Professor do Departamento de Serviço Social da Universidade Federal do Estado do Rio de Janeiro (Unirio)

\section{Unirio}

Avenida Pasteru, ${ }^{\circ} 458$ - Urca

Rio de Janeiro - RJ - Brasil

CEP: $22290-240$

\section{Agência financiadora}

Não se aplica.

Contribuições do autor

Não se aplica.

\section{Consentimento para publicação}

Não se aplica.

\section{Conflito de interesses}

Não há conflito de interesses.

Aprovação por Comitê de Ética e consentimento para participação

Não se aplica. 